\title{
Serotypes and antimicrobial resistance profiles of Salmonella isolates from pigs at slaughter in Kenya
}

\author{
Gideon M. Kikuvi ${ }^{1}$, Jackson N. Ombui ${ }^{2}$, Eric S. Mitema ${ }^{2}$ \\ ${ }^{1}$ Institute of Tropical Medicine and Infectious Diseases (ITROMID), Jomo Kenyatta University of Agriculture and \\ Technology, PO Box 62000 - 00200, Nairobi, Kenya \\ ${ }^{2}$ Department of Public Health Pharmacology and Toxicology, University of Nairobi, PO Box 29053 Nairobi, Kenya
}

\begin{abstract}
Background: Salmonellosis is considered one of the most widespread food-borne zoonoses in industrialized as well as developing countries. The presence of Salmonella in food animals at slaughter and the consequent cross-contamination of edible carcass tissues present a significant food safety hazard.

Methodology: Samples were collected from randomly selected pigs at the Ndumbuini abattoir in Nairobi. Isolates were confirmed to be Salmonella by biochemical tests and characterised by serotyping, phage typing and plasmid analysis. Minimum inhibitory concentrations (MICs) of eight antimicrobials were determined and the resistant isolates were screened for resistance genes by PCR.

Results: Sixteen (13.8\%) of 116 samples were positive for Salmonella. Three Salmonella enterica subsp. enterica serovars, namely Saintpaul, Braenderup, and Heidelberg were identified, S. Saintpaul being predominant. Antimicrobial resistance was found in $35.7 \%$ of the isolates. The $S$. Heidelberg isolates were susceptible to all the antimicrobials tested. Multidrug resistance was found in $7.1 \%$ of the Salmonella isolates. Plasmids were only detected in $S$. Heidelberg. Ampicillin resistance was based on expression of a bla $a_{\mathrm{TEM}}$ gene, while chloramphenicol, streptomycin, and tetracycline resistances were encoded by the genes catAl, strA, and tet(A), respectively.

Conclusions: Pigs may serve as reservoirs of antimicrobial resistant Salmonella and slaughterhouse cross-contamination of pork may be a food safety risk.
\end{abstract}

Key words: serotypes; antimicrobial resistance; Salmonella; pigs; Kenya

J Infect Dev Ctries 2010; 4(4):243-248.

(Received 25 August 2009 - Accepted 10 December 2009)

Copyright $\odot 2010$ Kikuvi et al. This is an open-access article distributed under the Creative Commons Attribution License, which permits unrestricted use, distribution, and reproduction in any medium, provided the original work is properly cited.

\section{Introduction}

Salmonellosis is one of the most widespread food-borne zoonoses in industrialized as well as developing countries [1]. In Kenya, non-typhoidal Salmonella species (NTS) are common causes of bacteraemia among immunocompromised individuals, infants and newborns [2]. Farm animals are the major reservoir for NTS in industrialized countries and large outbreaks of Salmonella infection have been associated with food-borne transmission including that from contaminated poultry and poultry products, meat, and milk and other dairy products [3]. Strains of the multidrug resistant (MDR) $S$. Typhimurium phage type (DT) 104, which have been responsible for epidemics particularly in Europe, the United States of America and Canada, represent reservoirs in cattle and are transmitted mainly through consumption of contaminated meat, milk and milk products [3]. MDR Salmonella strains have steadily increased, probably due to continuous antibiotic pressure in human and veterinary medicine [4].

Resistance, particularly to the commonly available antibiotics, poses a major health concern, as alternative therapeutic choices are either unavailable or too expensive to be affordable for most patients [2]. The genetic characterization of antimicrobial resistance genes as well as their location and diversity is important in identifying factors involved in resistance [5].

To date, few studies have analyzed the levels of resistance to antimicrobial agents in Salmonella serotypes isolated from pigs in Kenya [2]. Moreover, the mechanisms of resistance underlying the resistant phenotypes remain unknown. The present study was therefore conducted to estimate the prevalence of faecal carriage of Salmonella in healthy pigs at slaughter and of pig carcass contamination with 
Salmonella. Additionally, the antimicrobial susceptibility profiles and the genotypes of the resistant isolates were investigated.

\section{Materials and methods}

Sources of samples

Fresh faecal and carcass swab samples were collected from pigs at the Ndumbuini slaughterhouse in Nairobi. Pigs are sent to the abattoir from farms in Kiambu and Nairobi districts, which are among the main pig farming districts in Kenya. Pigs were selected at random and approximately $5 \mathrm{~g}$ of faeces was aseptically removed from the large bowel after evisceration at the slaughtering line. The carcasses were sampled using sterile cotton wool swabs. A surface approximately $100 \mathrm{~cm}^{2}$ around the hind limb (medial) and abdomen (lateral) was swabbed by wiping the cotton swabs on each sampling site five times in both vertical and horizontal directions. The samples were immediately placed into Stuart's transport medium (Oxoid, Basingstoke, United Kingdom), maintained on ice while being transported to the laboratory, and processed on the same day.

\section{Isolation and identification of Salmonella}

Faecal and swab samples were pre-enriched in buffered peptone water (Oxoid, Basingstoke, England) and incubated for 18 hours at $37^{\circ} \mathrm{C}$. A five millilitre aliquot of the pre-enrichment broth was transferred aseptically into tetrathionate broth (Oxoid) and incubated overnight at $37^{\circ} \mathrm{C}$. This step was followed by streaking aliquots from the enrichment broth onto deoxycholate citrate agar (DCA, Oxoid) plates, and incubating them at $37^{\circ} \mathrm{C}$ for 18 hours. From DCA plates, Salmonella-like colonies were tested on triple sugar iron agar (Oxoid) and urea agar (Oxoid) and confirmed biochemically using analytical profile index (API) 20E strips (bioMérieux, Marcy-I'Etoile, France).

The Salmonella isolates were serotyped and phage typed at the Robert Koch Institute, National Reference Centre for Salmonella and other Enteric Pathogens in Wernigerode, Germany, according to the Kauffmann-White Scheme [6]. To phage type the isolates, routine test dilutions of each of the typing phages were applied to nutrient agar (Difco, Detroit, USA) plates with a lawn of the respective bacterial strain using a multipoint inoculator. Plates were incubated at $37^{\circ} \mathrm{C}$ until the phage lysis result could be read and interpreted per the Anderson phage typing scheme [7].

\section{Minimum inhibitory concentration (MIC)} determination

MICs for ampicillin, tetracycline, streptomycin, kanamycin, sulphamethoxazole/trimethoprim gentamicin, $(19: 1)$ chloramphenicol, and nalidixic acid were determined using the standard broth dilution method with Mueller-Hinton ( $\mathrm{MH}$, Oxoid) medium, according to the methods described by the Clinical Laboratory and Standards Institute (CLSI) [8]. Escherichia coli ATCC 25922 (E. coli) was tested in parallel as a control. MICs were determined according to CLSI [9] except for streptomycin, for which the method of the Danish Integrated Antimicrobial Resistance Monitoring and Research Programme was followed [10].

\section{Plasmid analysis and PCR assays}

PCR assays were used for the detection of genes for ampicillin resistance (bla $a_{\mathrm{TEM}}$ and $\left.b l a_{\mathrm{PSE}}\right)$, tetracycline resistance $(\operatorname{tet}(\mathrm{A}), \operatorname{tet}(\mathrm{B}), \operatorname{tet}(\mathrm{C})$, and tet $(\mathrm{H})$ ), chloramphenicol resistance (catAl, catA3, and $c m l A$ ), and streptomycin resistance (strA and aadAl) as described previously $[11,12,13]$ using specific primers (Table 1). The plasmids and PCR products were detected by electrophoresis in $0.8 \%$ and $1.5 \%$ agarose gels, respectively. The plasmids of E. coli V517 (2.1 to $54 \mathrm{~kb})$, Klebsiella pneumoniae (R55, $150 \mathrm{~kb}$ ), and Salmonella Typhimurium LT2 $(90 \mathrm{~kb})$ served as molecular size standards for the plasmid preps [13], with a $1 \mathrm{~kb}$ ladder (Gibco BRL, Eggestein, Germany) for the PCR products. The migration distances of DNA bands were measured directly from photographs of the gels to determine plasmid sizes as per standard methods [14].

\section{Results}

\section{Isolation rate}

A total of 116 samples from pigs (carcass, $\mathrm{n}=58$ and faeces, $\mathrm{n}=58$ ) were obtained and analysed. Sixteen (13.8\%) of 116 samples were positive for Salmonella. Salmonella was isolated from 11 (19.0\%) of the carcass swabs and five $(8.6 \%)$ of the faecal samples. Salmonella was isolated from faeces and carcass swabs of the same animal only in two cases. Salmonella was found on the carcass but not in the faeces of nine pigs as compared to only one in which Salmonella was isolated from the faecal but not the carcass swab of the same animal. 
Distribution of Salmonella serotypes

Only 14 of the 16 Salmonella strains were able to grow from the lyophilized cultures and these strains were therefore sero- and phage typed. Three serovars were identified, with $S$. Saintpaul being predominant (9 strains) followed by $S$. Heidelberg (3 strains) and $S$. Braenderup (2 strains) (Table 2). Only the $S$.
Heidelberg isolates were phage typable and they belonged to phage type 02 . The highest proportion of S. Saintpaul $(7 / 9,77.8 \%)$ was

identified from carcass swabs as compared to faecal samples $(2 / 9,22.2 \%)$. On only one occasion $S$. Saintpaul was identified from the faecal and carcass

Table 1. Sequences of oligonucleotides used as primers and annealing temperatures for the detection of antimicrobial resistance determinants.

\begin{tabular}{|c|c|c|c|c|}
\hline Target gene/Primer & Oligonucleotide sequence $\left(5^{\prime} \rightarrow 3^{\prime}\right)$ & $\begin{array}{l}\text { Amplicon size } \\
\text { (bp) }\end{array}$ & $\begin{array}{l}\text { Annealing } \\
\text { temp }\left({ }^{\circ} \mathrm{C}\right)\end{array}$ & $\begin{array}{c}\text { Reference sequence } \\
\text { (Genbank Accession number(s)) }\end{array}$ \\
\hline $\operatorname{aadAl}$ & $\begin{array}{l}\text { f:- GTGGATGGCGGCCTGAAGCC } \\
\text { r:- ATTGCCCAGTCGGCAGCG }\end{array}$ & 527 & 56 & $\begin{array}{l}\text { Escherichia coli } \\
\text { (M10241, X02340) }\end{array}$ \\
\hline catAl & $\begin{array}{l}\text { f:- GGCATTTCAGTCAGTTG } \\
\text { r:- CATTAAGCATTCTGCCG }\end{array}$ & 551 & 50 & $\begin{array}{l}\text { Tn9 E. coli } \\
\text { (V00622) }\end{array}$ \\
\hline catA3 & $\begin{array}{l}\text { f:- ACCATGTGGTTTTAGCTTAACA } \\
\text { r:- GCAATAACAGTCTATCCCCTTC }\end{array}$ & 473 & 56 & $\begin{array}{l}\text { Uncultured eubacterium } \\
\qquad(\mathrm{AJ} 271879)\end{array}$ \\
\hline cmlA & $\begin{array}{l}\text { f:- CCGCCACGGTGTTGTTGTTATC } \\
\text { r:- CACCTTGCCTGCCCATCATTAG }\end{array}$ & 698 & 40 & $\begin{array}{l}\text { Pseudomonas aeruginosa } \\
\text { (M64556) }\end{array}$ \\
\hline$b l a_{\mathrm{TEM}}$ & $\begin{array}{l}\text { f:- CCGTGTCGCCCTTATTCCC } \\
\text { r:- GCCTGACTCCCCGTCGTGT }\end{array}$ & 780 & 51 & $\begin{array}{l}\text { Enterobacter cloacae } \\
\text { AY302260 }\end{array}$ \\
\hline$b l a_{\mathrm{PSE}}$ & $\begin{array}{l}\text { f:- CGCTTCCCGTTAACAAGTAC } \\
\text { r:- CTGGTTCATTTCAGATAGCG }\end{array}$ & 465 & 58 & $\begin{array}{l}\text { Salmonella Typhimurium } \\
\text { AF153200 }\end{array}$ \\
\hline strA & $\begin{array}{l}\text { f:- GACTGGTTGCCTGTCAGAGG } \\
\text { r:- CAGTTGTCTTCGGCGTTAGCA }\end{array}$ & 646 & 64 & $\begin{array}{c}\text { Plasmid RSF } 1010 \\
\text { M28829 }\end{array}$ \\
\hline $\operatorname{tet}(\mathrm{A})$ & $\begin{array}{l}\text { f:- GTAATTCTGAGCACTGT } \\
\text { r:- CCTGGACAACATTGCTT }\end{array}$ & 954 & 45 & $\begin{array}{l}\text { RP1 from E. coli } \\
\quad(\mathrm{X} 00006)\end{array}$ \\
\hline $\operatorname{tet}(\mathrm{B})$ & $\begin{array}{l}\text { f:- ACGTTACTCGATGCCAT } \\
\text { r:- AGCACTTGTCTCCTGTT }\end{array}$ & 1170 & 48 & $\begin{array}{l}\text { Tn10 from Shigella flexneri } \\
\text { (J01830) }\end{array}$ \\
\hline $\operatorname{tet}(\mathrm{C})$ & $\begin{array}{l}\text { f:- AACAATGCGCTCATCGT } \\
\text { r:- GGAGGCAGACAAGGTAT }\end{array}$ & 1138 & 50 & $\begin{array}{l}\text { pSC101 from Salmonella } \\
\text { Typhimurium (X01654) }\end{array}$ \\
\hline $\operatorname{tet}(\mathrm{H})$ & $\begin{array}{l}\text { f:- ATACTGCTGACACCGT } \\
\text { r:- TCCCAATAAGCGACGCT }\end{array}$ & 1076 & 50 & $\begin{array}{l}\text { pVM111 from Pasteurella } \\
\text { multocida }(\text { S52437) }\end{array}$ \\
\hline
\end{tabular}

f, forward primer; $r$, reverse primer

Table 2. Serotype, source and antimicrobial resistance profiles of Salmonella isolates from pig faecal and carcass samples.

\begin{tabular}{|c|c|c|c|c|c|}
\hline $\begin{array}{c}\text { Pig } \\
\text { Number }\end{array}$ & Salmonella serovar & Source & Resistance pattern & $\begin{array}{c}\text { Resistance gene(s) } \\
\text { detected }\end{array}$ & $\begin{array}{l}\text { Approximate plasmid } \\
\text { size }(\mathrm{kb})\end{array}$ \\
\hline 1 & $S$. Heidelberg & carcass & susceptible & ND & 40,80 \\
\hline 2 & $S$. Heidelberg & carcass & susceptible & ND & 40,80 \\
\hline 3 & $S$. Heidelberg & carcass & susceptible & ND & $40,54,80$ \\
\hline \multirow[t]{2}{*}{4} & $S$. Braenderup & faeces & $\mathrm{Amp}^{\mathrm{R}} \mathrm{Sm}^{\mathrm{R}} \mathrm{Tet}^{\mathrm{R}}$ & $b l a_{\mathrm{TEM}}, \operatorname{str} A, \operatorname{tet}(\mathrm{A})$ & none \\
\hline & $S$. Braenderup & carcass & susceptible & ND & none \\
\hline 5 & S. Saintpaul & carcass & susceptible & ND & none \\
\hline 6 & S. Saintpaul & carcass & susceptible & ND & none \\
\hline 7 & S. Saintpaul & faeces & $A m p^{R}$ & $b l a_{\mathrm{TEM}}$ & none \\
\hline 8 & S. Saintpaul & carcass & susceptible & ND & none \\
\hline \multirow[t]{2}{*}{9} & S. Saintpaul & carcass & Tet $^{\mathrm{I}}$ & $\operatorname{tet}(\mathrm{A})$ & none \\
\hline & S. Saintpaul & faeces & $\mathrm{Cm}^{\mathrm{R}}$ & catAl & none \\
\hline 10 & S. Saintpaul & carcass & $\mathrm{Sm}^{\mathrm{R}}$ & strA & none \\
\hline 11 & S. Saintpaul & carcass & susceptible & ND & none \\
\hline 12 & S. Saintpaul & carcass & susceptible & ND & none \\
\hline
\end{tabular}

Amp, ampicillin; $\mathrm{Cm}$, chloramphenicol; Sm, streptomycin; Tet, tetracycline; ${ }^{\mathrm{R}}$, resistant;

${ }^{\mathrm{I}}$, intermediately resistant; ND, not done. N.B. Two faeces samples could not be grown from lyophilized culture and are therefore not shown in this table. 
swab samples obtained from the same animal. Both $S$. Braenderup isolates were from the same animal. All three $S$. Heidelberg isolates were obtained from carcass swabs. No more than one serovar was isolated from the same animal.

\section{Antimicrobial susceptibility}

All three $S$. Heidelberg and five of the nine $S$. Saintpaul isolates were susceptible to all eight antimicrobials tested. In contrast, one $S$. Braenderup isolate, from a faecal sample, was resistant to ampicillin, tetracycline, and streptomycin while the other was susceptible to all antimicrobials tested. Three out of the four $S$. Saintpaul isolates showing resistance were fully resistant to one of chloramphenicol, streptomycin or ampicillin, whereas the fourth strain was intermediately resistant to tetracycline. Resistance to ampicillin and chloramphenicol was only observed in the faecal isolates while resistance to streptomycin or tetracycline was observed in both faecal and carcass isolates. All isolates were susceptible to gentamicin, kanamycin, sulphamethoxazole/trimethoprim and nalidixic acid.

\section{Plasmid analysis and antimicrobial resistance genotyping}

All the isolates were plasmid free except for the three $S$. Heidelberg isolates. All three isolates harboured two large plasmids ( 40 and $80 \mathrm{~kb}$ in size) while one also possessed a third plasmid $(\sim 54 \mathrm{~kb})$. The PCR results were consistent with the antimicrobial susceptibility phenotypes. The $b l a_{\text {TEM }}$ gene was detected in each of the ampicillin-resistant Salmonella isolates while the $\operatorname{str} A$ gene was detected in each of the streptomycin-resistant isolates. The catAl and tet(A) genes were detected in the chloramphenicol and tetracycline resistant isolates, respectively.

\section{Discussion}

The present study detected a moderately high prevalence (12/58 pigs; $20.7 \%$ ) of Salmonella spp. in pigs. In fact, Salmonella infection persists in pig herds in the subclinical stage and pigs are often clinically asymptomatic carriers of Salmonella [15], which might be attributable to the isolation of Salmonella from apparently healthy pigs. The prevalence of Salmonella on pig carcasses (19\%) was higher than in faeces $(8.6 \%)$. A higher prevalence of apparently different Salmonella strains on carcasses than in faeces suggests the presence of environmental contamination during the slaughtering process. About $79 \%$ of the pigs in this study had culture-positive carcass swab samples and culture-negative faeces (data not shown). The major contamination sources of pig carcasses have been shown to be either pig(faeces, pharynx and stomach) or environmentrelated (contact surfaces and handling by Salmonellacarrying slaughterhouse personnel) [1]. Serological monitoring of pig herds is essential for the identification of Salmonella in the pork production chain [16]. In nine pigs, Salmonella was found on the carcass but not in the faeces. This may have been a result of cross-contamination from adjacent positive carcasses on the dressing line [17] that may or may not have been part of the sample carcasses. Alternatively, contaminated abattoir equipment or floors, or Salmonella-shedding slaughterhouse personnel [2] may have been the source. In $18.2 \%$ $(2 / 11)$ of the positive carcasses, the same Salmonella serovar was isolated from the carcass and faeces of the same pig. Poor evisceration technique was probably the reason for this contamination. Paying attention to the technique can reduce faecal contamination of the carcasses although transmission of Salmonella from the environment could also occur, via the slaughterhouse personnel or the equipment [18].

$S$. Saintpaul was the most frequently isolated serovar followed by $S$. Heidelberg and $S$. Braenderup. This observation is contrary to that of a previous study in Kenya [2] which found $S$. Agona to be the main serotype in pigs. As demonstrated by Botteldoorn et al., this disparity might be due to differences in the period of sampling, the various slaughterhouses, or the origin and number of infected pigs [16]. The observation that $S$. Heidelberg accounted for approximately one fifth of the total isolates appears to be the first report of this strain in food animals in Kenya.

The majority $(9 / 14,64.3 \%)$ of the Salmonella isolates in this study were susceptible to all eight antimicrobials tested with all the isolates susceptible to gentamicin, kanamycin, sulphamethoxazole/trimethoprim and nalidixic acid. Similar observations were made in the analysis of NTS serovars from chicken, pigs, and beef cattle in Kenya [2]. Due to the relatively low cost and ready availability of ampicillin, tetracycline and streptomycin, these antimicrobial agents are widely used by farmers for therapeutic and prophylactic applications [2]. Although, in Kenya, neither chloramphenicol nor its fluorinated analog, 
florfenicol is approved for use in food animals, chloramphenicol resistance was still detected in one faecal isolate. This observation might be due to the acquisition of resistance genes from other sources, such as bacteria in water contaminated with human sewage or due to illegal use of chloramphenicol. Chloramphenicol resistance genes have often been associated with either multiresistance conjugative transposons or plasmid-borne multiresistance integrons which are mobile genetic elements detected in a variety of enterobacterial species [19].

Plasmids were detected only in the $S$. Heidelberg isolates. Each of the two ampicillin-resistant isolates in this study contained the $b l a_{\mathrm{TEM}}$ gene. The $b l a_{\mathrm{TEM}}$ gene is usually part of transposon $\mathrm{Tn} 3$ and has been found previously among Salmonella isolates [10]. The strA gene was detected in each of the two streptomycin-resistant isolates. The gene $s t r A$, which may be part of transposon Tn5393, has been found frequently among streptomycin-resistant isolates, such as Salmonella Typhimurium [6,11]. Chloramphenicol resistance was based on expression of the catAl gene. The Tn9-associated catAl has been detected previously in Salmonella isolates, but is also widespread among other Gram negative bacteria [11]. Tetracycline resistance was mediated by the $\operatorname{tet}(\mathrm{A})$ gene. The tet(A) gene is located frequently on transposons such as $\operatorname{Tn} 1721$, and the gene has been found to be widespread among Gram negative bacteria including salmonellae $[5,20]$.

The present study revealed the occurrence of antimicrobial resistant Salmonella in pigs at slaughter and on pork carcasses in Kenya. This observation indicates the potential importance of pigs as a source of single and multiple antimicrobial-resistant Salmonella isolates to commonly used antimicrobials including ampicillin, chloramphenicol, streptomycin and tetracycline. This calls for measures to control the occurrence of Salmonella in pigs and pork carcasses. Resistance was encoded by genes that are widespread in other Enterobacteriaceae and that are known to be commonly located on transposons, mobile genetic elements that play an important role in the transmission and dissemination of antimicrobial resistance determinants.

\section{Acknowledgements}

This study was supported by a scholarship from the German Academic Exchange Service (DAAD). The authors thank Dr W. Rabsch of the Robert Koch Institute, National Reference Centre for Salmonella and other Enteric Pathogens, Wernigerode, Germany, for serotyping and phage typing of the Salmonella isolates.

\section{References}

1. Molla B, Alemayehu D, Salah W (2003) Sources and distribution of Salmonella serotypes isolated from food animals, slaughterhouse personnel and retail meat products in Ethiopia 1997-2002. Ethio J Hlth Dev 17: 63-70.

2. Kariuki S, Revathi G, Gakuya F, Yamo V, Muyodi J, Hart A (2002) Lack of clonal relationship between non-typhi Salmonella strains types from humans and those from animals living in close contact. FEMS Immunol Med Microbiol 33: 165-71.

3. Threlfall EJ (2000) Epidemic Salmonella Typhimurium DT 104 - a truly international multiresistant clone. J Antimicrob Chemother 46: 7-10.

4. Orman B, Pineiro SA, Arduino S, Galas M, Melano R, Caffer MI, Sordelli DO, Centron,D (2002) Evolution of multiresistance in nontyphoid Salmonella serovars from 1984 in Argentina. Antimicrob Agents Chemother 46: 396370.

5. Gebreyes WA and Altier C (2002) Molecular characterization of multidrug-resistant Salmonella enterica subsp. enterica serovar Typhimurium isolates from swine. J Clin Microbiol 40: 2813-22.

6. Popoff MY, Bockemuh J, Gheesling LL (2003) Supplement 2001 (No. 45) to the Kauffmann-White scheme. Res Microbiol 154: 173-74.

7. Anderson E S, Ward LR, de Saxe MJ, de Sa JD (1977). Bacteriophage-typing designations of Salmonella typhimurium. J Hyg 78: 297-300.

8. NCCLS (2004) National Committee for Clinical Laboratory Standards, Performance Standards for antimicrobial disk and dilution susceptibility tests for bacteria isolated from animals, informational supplement NCCLS Document M31S1, vol. 24, No. 17 National Committee for Clinical Laboratory Wayne Pennsylvania, USA.

9. NCCLS (2003) National Committee for Clinical Laboratory Standards, Methods for dilution antimicrobial susceptibility tests for bacteria that grow aerobically, sixth edition, approved standard. M7-A6. NCCLS, Wayne, PA, USA.

10. DANMAP (2001) Use of antimicrobial agents and occurrence of antimicrobial resistance in bacteria from food animals, foods and humans ISSN 1600-2032.

11. Frech G, Kehrenberg C, Schwarz S (2003) Resistance phenotypes and genotypes of multiresistant Salmonella enterica subsp. enterica serovar Typhimurium var Copenhagen isolates from animal sources. J Antimicrob Chemother 51: 180-82.

12. Kehrenberg C and Schwarz S (2001) Occurrence and linkage of genes coding for resistance to sulfonamides, streptomycin and chloramphenicol in bacteria of the genera Pasteurella and Mannheimia. FEMS Microbiol Lett 205: 283-90.

13. Blickwede M and Schwarz S (2004) Molecular analysis of florfenicol-resistant Escherichia coli isolates from pigs. J Antimicrob Chemother 53: 58-64.

14. Wand M, Tran J H, Jacoby GA, Zhang Y, Wang F, Hooper DC (2003) Plasmid-mediated quinolone resistance in clinical isolates of Escherichia coli from Shanghai China. Antimicrob Agents Chemother 47: 2242-48.

15. Bywater R, Deluyker H, Derooker E, de Jong A, Marion H, McConville V, Rowan T, Shryock T, Shuster D, Thomas V, Valle M, Walters J (2004) European survey of antimicrobial susceptibility among zoonotic and commensal bacteria 
isolated from food-producing animals. $\mathrm{J}$ Antimicrob Chemother 54: 744-54.

16. Botteldoorn N, Heyndrickx M, Rijpens N, Grijspeerdt K, Herman L (2003) Salmonella on pig carcasses: positive pigs and cross contamination in the slaughterhouse. J Appl Microbiol 95: 891-903.

17. Ejeta G, Molla B, Alemayehu D, Muckle A (2004) Salmonella serotypes isolated from minced meat beef, mutton and pork in Addis Ababa Ethiopia. Rev Med Vet 155: 547-51.

18. McEvoy JM, Doherty AM, Sheridan JJ, Blair IS, McDowell DA (2003) The prevalence of Salmonella spp. in bovine faecal, rumen and carcass samples at a commercial abattoir. J Appl Microbiol 94: 693-700.

19. Pai H, Byeon JH, Yu S, Lee BK, Kim S (2003) Salmonella enterica serovar Typhi strains isolated in Korea containing a multidrug resistance class 1 integron. Antimicrob Agents Chemother 47: 2006-08.

20. Pasquali F, Kehrenberg C, Manfreda G, Schwarz S (2005) Physical linkage of Tn3 and part of Tn1721 in a tetracycline and ampicillin resistance plasmid from Salmonella Typhimurium. J Antimicrob Chemother 55: 562-65.

\section{Corresponding author}

Gideon M. Kikuvi

Institute of Tropical Medicine and Infectious Diseases

(ITROMID)

Jomo Kenyatta University of Agriculture and Technology

PO Box 62000 - 00200, Nairobi, Kenya

Email: kikuvi@yahoo.com

Conflict of interests: No conflict of interests is declared 